\title{
Continuous Cell Line from Pupal Ovary of Perina nuda (Lepidoptera: Lymantriidae) That Is Permissive to Nuclear Polyhedrosis Virus from P. nuda
}

\author{
Chung-Hsiung Wang, ${ }^{*}$ Chin-Ming Chou, $\dagger$ Hwei-Chung LiU, $*$ Shih-Liang KaU, $\ddagger$ Guang-Hsung Kou, $\dagger$ AND \\ ChU-FANG Lo $\dagger$
}

Departments of *Plant Pathology and Entomology and $†$ Zoology, National Taiwan University, Taipei, Taiwan, ROC; and $\ddagger$ Pathology Department, Veterans-General Hospital, Taipei, Taiwan, ROC

Received February 2, 1995; accepted November 14, 1995

\begin{abstract}
A continuous cell line, designated NTU-PN-HH, was established from the pupal ovary of Perina nuda Fabricius (Lepidoptera: Lymantriidae). The cells have been through more than 300 passages during 4 years in TNM-FH medium supplemented with $10 \% \mathrm{FBS}$, at a constant temperature of $28^{\circ} \mathrm{C}$. The cell line consists of four major morphologic types: polymorphic cells, spindle-shaped cells, round cells, and squamous cells. The characterization of this cell line showed that NTUPN-HH is a newly established cell line. It is the first cell line that is permissive to PnNPV (P. nuda multiple nuclear polyhedrosis virus). ๑ 1996 Academic Press, Inc.

Key WORDS: Perina nuda; NTU-PN-HH cell line; PnNPV.
\end{abstract}

\section{INTRODUCTION}

Many Lepidopteran cell lines have been established since 1962 (Grace, 1962; Hink, 1970, 1980), several of which have been successfully used to multiply nuclear polyhedrosis virus (NPV) (Wu et al., 1989). These virus-permissive cell lines have contributed significantly to pest control (Smiths and Vlak, 1988) and to the production of recombinant proteins (Fraser, 1989; Maeda et al., 1985; Smith et al., 1983; Wu et al., 1989). Over 600 isolates of baculoviruses have been found, but the study of most of these have been limited by a lack of susceptible cell lines on which to propagate these viruses (Gelernter and Federici, 1986). To facilitate further study of baculoviruses, it is necessary to establish an insect cell line of high viral susceptibility.

Perina nuda (Fabricius) is a major pest of banyan (Ficus spp.), an important garden tree in Taiwan and mainland China. The larvae of $P$. nuda are external feeders on foliage and cause the destruction of tree leaves. The epizootic disease occurs every year from spring to early summer in Taiwan and mainland China. The key pathogen was found to be baculovirus PnNPV ( $P$. nuda multiple nuclear polyhedrosis virus)
(Su et al., 1983; Lo et al., 1990; Wang and Tsai, 1995). Because there were no permissive cell lines for PnNPV, the study of this virus has been limited to morphological descriptions. We have established a permissive cell line derived from pupal ovary of $P$. nuda, which represents a great hope for extensive study of PnNPV at the pathologic, cellular, and molecular levels.

\section{MATERIALS AND METHODS}

\section{Primary Culture and Subculture}

Larvae of $P$. nuda were collected from the campus of National Taiwan University, and fed banyan leaves at $25^{\circ} \mathrm{C}$. The larvae were allowed to go through the pupal stage, after which the pupae were collected and sterilized with a $10 \%$ Clorox solution and $70 \%$ iodine alcohol. The ovaries were removed with a fine forceps and a pipet, and incubated at $28^{\circ} \mathrm{C}$ in TNM-FH medium (Hink and Strauss, 1976) containing $100 \mathrm{IU} / \mathrm{ml}$ penicillin, $100 \mu \mathrm{g} / \mathrm{ml}$ streptomycin, and $1.25 \mu \mathrm{g} / \mathrm{ml}$ fungizone. The medium was supplemented with $10 \%$ fetal bovine serum (FBS) that had been inactivated at $56^{\circ} \mathrm{C}$ for $30 \mathrm{~min}$.

The cells were subcultured when approaching confluency. During the first 25 passages, the cells adhering to the bottom of the flask had to be removed with a rubber policeman, but thereafter could be resuspended by vigorous agitation. When subculturing, $1 \mathrm{ml}$ of suspended cells were transferred to a new $25 \mathrm{~cm}^{2}$ flask containing $4 \mathrm{ml}$ of fresh media plus supplements. From the initial subculture to the 40th passage, the interval between subcultures ranged from 1 to 3 weeks, depending on the growth rate of the cells. After the 49th passage, the cells propagated rapidly, and thereafter the interval between passages was 4 days. The resulting cell line has been designated NTU-PN-HH.

\section{Susceptibility of Virus}

The following viruses were used to test the viral susceptibility of NTU-PN-HH cells: AcNPV (Autographa 
californica NPV) and HzNPV (Heliothis zea NPV), kindly supplied by Dr. M. J. Fraser of Notre Dame University; BmNPV (Bombyx mori NPV) collected from infected Bm-N cells or infected larvae of $B$. mori and PnNPV collected from infected larvae of $P$. nuda.

These four viruses were used to examine the viral susceptibility of three other cell lines as a positive control for virus infectivity (IPLB-SF-21AE, Bm-N, and IPLB-HZ-1075 [H. zea cell line]) (Goodwin et al., 1982; Maeda, 1989; Vaughn et al., 1977). AcNPV, HzNPV, and BmNPV were obtained from their permissive cell lines, IPLB-SF-21AE, IPLB-HZ-1075, and Bm-N, respectively. The semiconfluent tested cells (log-phase cells) of NTU-PN-HH were inoculated with the filtered homogenate of infected $P$. nuda larvae or the filtered culture medium of the NPV-infected cells of IPLB-SF21AE, IPLB-HZ-1075, and Bm-N. After $1 \mathrm{hr}$ of adsorption, the viral solution was discarded and the cells were incubated in fresh TNM-FH medium at $28^{\circ} \mathrm{C}$. The cytopathic effect (CPE) was observed and documented. The virus titer was determined by the end-point dilution method (TCID $_{50}$ analysis) (Summers and Smith, 1988).

\section{Electron Microscopy}

The infected cells were scraped from the surface of the plastic flasks and sedimented at $900 \mathrm{rpm}$. The medium was discarded and the pellets were fixed in $2.5 \%$ glutaraldehyde in $\mathrm{pH} 7.2$ phosphate buffer at $4^{\circ} \mathrm{C}$ for 3 $\mathrm{hr}$ and postfixed in $1 \% \mathrm{OsO}_{4}$ in the same buffer for $2 \mathrm{hr}$. The pellets were then dehydrated in an alcohol gradient series and embedded in Spurr Epon. Thin sections were cut on a Reichert OMU 3 ultramicrotome and stained with uranyl acetate and lead citrate. The photomicrographs were made with a Hitachi H7100 electron microscope at $100 \mathrm{kV}$.

\section{Chromosome Number}

The NTU-PN-HH chromosome spreads were prepared by treating $5 \mathrm{ml}$ of log-phase cultures $\left(2 \times 10^{6}\right.$ cell $\mathrm{s} / \mathrm{ml}$ ) with $0.06 \mu \mathrm{g} / \mathrm{ml}$ demecolcine (Sigma, D-6279) for $2 \mathrm{hr}$ at $28^{\circ} \mathrm{C}$. The cells were dispersed and centrifuged (900 rpm) for $5 \mathrm{~min}$, resuspended for $10 \mathrm{~min}$ in a hypotonic solution of normal saline and distilled water in a 1:4 dilution, and then fixed in 3:1 methanol:glacial acetic acid for $20 \mathrm{~min}$. The fixed cells were dropped vertically onto the slides. After air drying, the cells were stained with Giemsa stain for $30 \mathrm{~min}$ and the chromosome number was counted under a microscope.

\section{Growth Rate of NTU-PN-HH Cells}

The NTU-PN-HH cells were seeded in $25 \mathrm{~cm}^{2}$ flasks, about $1 \times 10^{6}$ cells each, and cultured with $0,5,10$, and $20 \%$ FBS supplementation at $28^{\circ} \mathrm{C}$, and at $4,20,28$, and $37^{\circ} \mathrm{C}$ with $10 \%$ FBS supplementation. The cul- tured cells were counted with a hemocytometer every $24 \mathrm{hr}$ for 6 days.

\section{Isozyme Analysis}

The confluent cells of NTU-PN-HH, IPLB-SF-21AE, and IPLB-LD-652Y (Lymantria dispar cell line) (Goodwin et al., 1978) were collected and centrifuged at 900 rpm for $10 \mathrm{~min}$ at $4^{\circ} \mathrm{C}$. The pellets were washed twice in phosphate-buffered saline (PBS) and then resuspended in a grinding buffer $(0.125 \mathrm{M}$ Tris, $0.046 \mathrm{M}$ citric acid, $10 \%$ sucrose, $1 \%$ Triton X-100, and $0.02 \mathrm{mM}$ bromophenol blue). The cells were frozen in liquid nitrogen and thawed $\left(37^{\circ} \mathrm{C}\right)$ three times and then cell lysates were centrifuged at $15,000 \mathrm{~g}$ for $5 \mathrm{~min}$. The supernatant liquid was stored at $-20^{\circ} \mathrm{C}$.

Following electrophoresis on $5 \%$ polyacrylamide gels, the cell lysates were tested for isozymes, esterase, lactate dehydrogenase (LDH), and malate dehydrogenase (MDH). The upper tank buffer consisted of 0.005 $M$ Tris and $0.036 M$ glycine ( $\mathrm{pH} 8.3$ ), and the lower tank buffer consisted of $0.0375 M$ Tris (pH 8.9). Vertical slab gels were run at a constant current of $20 \mathrm{~mA}$ for $3 \mathrm{hr}$ and then stained following the protocol of Harris and Hopkinson (1977).

\section{Restriction and Electrophoresis of DNA}

The isolation and purification of polyhedra and virus particles, and DNA preparation of PnNPV from moribund $P$. nuda larvae and infected NTU-PN-HH cells were achieved as described by Summers and Smith (1988). Both DNAs were digested with EcoRI, Hind III and Pst I (Promega Corporation), according to the user's manual, and analyzed in $0.7 \%$ agarose gels.

\section{RESULTS}

The cell line derived from pupal ovary of $P$. nuda was established in vitro and designated NTU-PN-HH. Four major morphologically different cell types (polymorphic, spindle-shaped, round, and squamous) were observed in the primary cell culture. These four cell types were still present after 50 passages, though the polymorphic cells and squamous cells became dominant. The cells have been passaged for more than 4 years in TNM-FH medium containing 10\% FBS under a constant temperature of $28^{\circ} \mathrm{C}$.

The four major types of NTU-PN-HH cell are easily distinguished after plating for $1 \mathrm{hr}$. The characteristics of these four cells are as follows (Fig. 1A).

The polymorphic cells ( $\mathrm{P}$ cells) are irregular in shape and varied in size (20-50 $\mu \mathrm{m}$ wide and 50-90 $\mu \mathrm{m}$ long). The plasma membrane of one side is generally smooth, but the opposite side spreads on the substratum with an irregular margin containing many processes. The nucleus is round or ellipsoid, varied in size (10-25 $\mu \mathrm{m}$ wide and 20-30 $\mu \mathrm{m}$ long), and excentrically located near the smooth margin of the cell. 

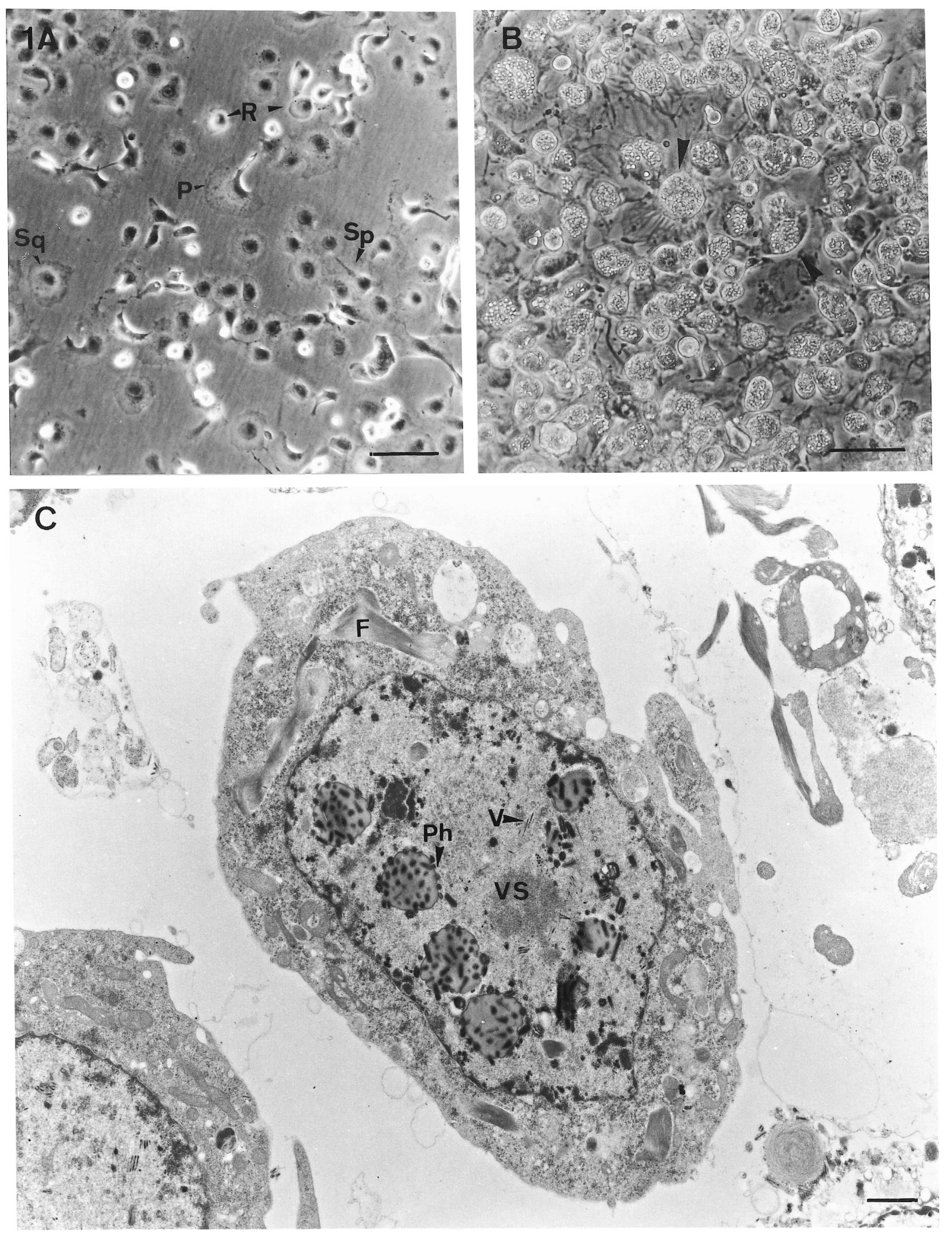

FIG. 1. The characteristic of the NTU-PN-HH cell line established from pupae of Perina nuda, showing: (A) Four major cell types in the NTU-PN-HH cell line, polymorphic cells (P), spindle-shaped cells (Sp), squamous cells (Sq), and round cells (R). Bar, $50 \mu \mathrm{m}$. (B) The infected cells, 7 days after infection with PnNPV. Note that more than $98 \%$ of the cells are susceptible to PnNPV and the hypertrophied nuclei of infected cells fill with polyhedra (arrows). Bar, $50 \mu \mathrm{m}$. (C) The electron micrograph of a NTU-PN-HH cell infected with MP strain of PnNPV at 3 days after viral inoculation. Note the virion (V) adjacent to virogenic stroma (VS). The developing polyhedra (Ph) in the hypertrophied nucleus are surrounding virogenic stroma and the fibrillar materials $(\mathrm{F})$ located in cytoplasm and nucleus. Bar, $0.1 \mu \mathrm{m}$. 
The spindle-shaped cells (Sp cells) are predominantly ellipsoidal, with two extensions (on opposite sides) and varied in size (8-16 $\mu \mathrm{m}$ wide and $65-110$ $\mu \mathrm{m})$. Both or one of the extensions spread on the substratum, with several processes. The cells are able to continue growing on the confluent monolayer, eventually forming a superimposed layer of cells easily detached from the substrate. The nucleus is round or elliptical, centrally located, and almost fills the cell.

The round cells ( $\mathrm{R}$ cells) are small cells, have a high nucleo-cytoplasmic ratio, and are $20-28 \mu \mathrm{m}$ in diameter. The nucleus is large, centrally located, and almost fills the cell. The majority of the cells are loosely attached to the substratum, occasionally with one or two tiny filipodia, and the cells form aggregates, especially on confluency.

The squamous cells (Sq cells) are large and varied in size (20-80 $\mu \mathrm{m}$ in diameter). The cells are spreading and adhere firmly to the substrate with processes. The nucleus is round, centrally located, and 13-30 $\mu \mathrm{m}$ in diameter. The cytoplasm may contain granules or vacuoles, especially on confluency.

NTU-PN-HH cells showed a high susceptibility to PnNPV in vitro (Fig. 1B). No cytopathic effect was detected in NTU-PN-HH cells after inoculation with $\mathrm{HzNPV}$ and BmNPV, whereas a few NTU-PN-HH cells showed a lysis effect after inoculation with AcNPV, especially at lower osmotic pressures (less than 315 milliosmol), but the cells recovered after 3 days of inoculation. The MP strain of PnNPV was isolated in vitro and the average yield of PIB per NTU-PN-HH cell was 35. After inoculation with PnNPV MP strain, 98\% of NTU-PN-HH cells produced the polyhedral inclusion bodies (PIBs) (Fig. 1B) and the virus titer increased from $\mathrm{TCID}_{50 / \mathrm{ml}}=10^{-5.61 \pm 0.81}$ to $10^{-8.72 \pm 0.72}$. The morphogenesis and infectivity of PnNPV in vitro was similar to that in vivo. After 5 days of infection, nucleocapsids, multiple nucleocapsid virions, virogenic stroma, and developing polyhedra were observed in the hypertrophied nuclei, and fibrillar materials were found in the cytoplasm and nucleus. The plasma membrane and nuclear envelope remained intact and showed no sign of destruction. The ultrastructural morphogenesis of PnNPV in vitro revealed that PnNPV is a typical NPV (Fig. 1C).

A representative chromosomal spread from NTU$\mathrm{PN}-\mathrm{HH}$ cells shows the typical round shape of Lepidopteran chromosome (Fig. 2A). The distribution of chromosome numbers varied widely from 52 to 285 , with an average of 117 (Fig. 2B). The influence of various concentrations of FBS on the growth rate of NTU-PN-HH cells at a constant temperature of $28^{\circ} \mathrm{C}$ indicated that 10 and $20 \%$ FBS stimulated cell growth better than did 0 and 5\% (Fig. 3A). The doubling times for cell population in TNM-FH medium with 10 and $20 \%$ FBS at $28^{\circ} \mathrm{C}$ were 86 and $54 \mathrm{hr}$, respectively. The doubling times of NTU-PN-HH cells were also recorded after cultivating the cells in TNM-FH medium supplemented with $10 \% \mathrm{FBS}$ at different temperatures. The maximum growth rate of the cells was at $28^{\circ} \mathrm{C}(86 \mathrm{hr}$ doubling time). The cells grew very slowly at 4 and $37^{\circ} \mathrm{C}$ and eventually died, whereas at $20^{\circ} \mathrm{C}$, the cells remained viable; cell growth continued slower than at $28^{\circ} \mathrm{C}$ (94 hr doubling time) (Fig. 3B).

The mobility of esterase, $\mathrm{LDH}$, and $\mathrm{MDH}$ from NTU$\mathrm{PN}-\mathrm{HH}$ cells was different from that from IPLB-SF21AE and IPLB-LD-652Y cells (Fig. 4). The restriction endonuclease fragment patterns of the PnNPV DNAs purified from in vivo and in vitro were identical for EcoRI, HindIII, and PstI (Fig. 5).

\section{DISCUSSION}

The cell line derived from $P$. nuda pupal ovary has been designated NTU-PN-HH. NTU-PN-HH cell line is the second viral-susceptible cell line derived from the
A

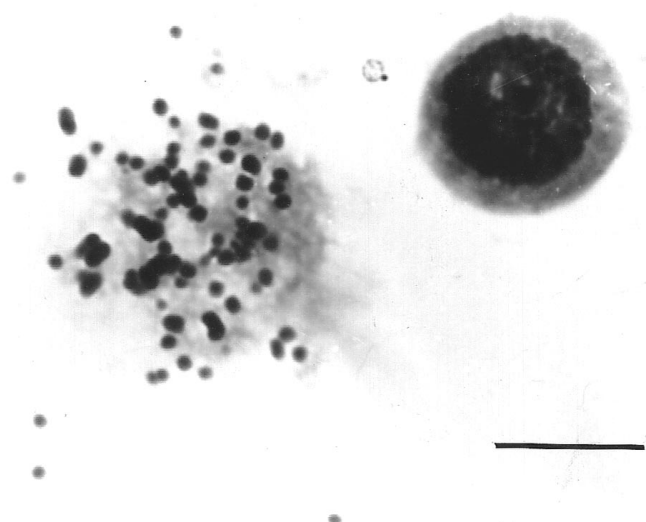

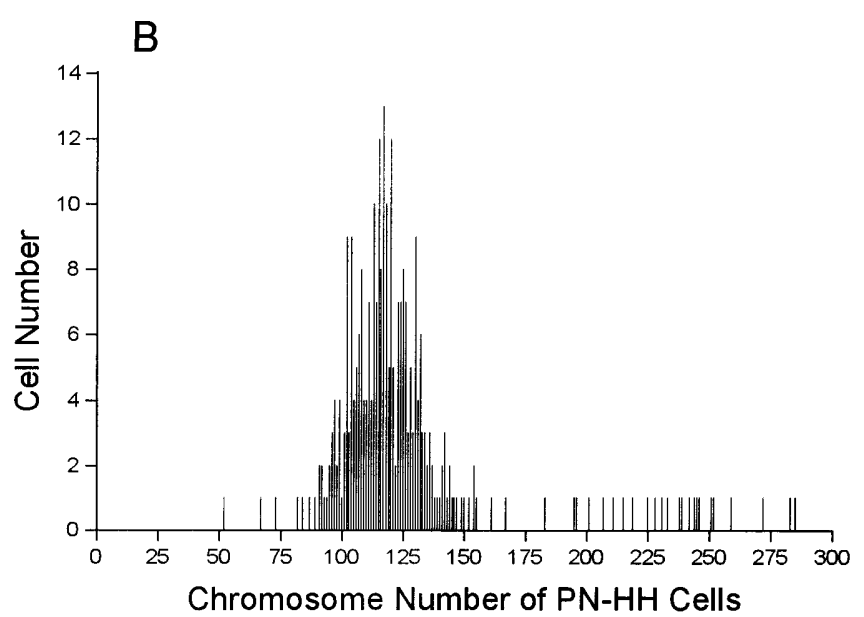

FIG. 2. A representative mitotic chromosomal spread obtained from NTU-PN-HH cells (A) and the distribution of chromosome number in NTU-PN-HH cell population (B). Bar, $10 \mu \mathrm{m}$. 


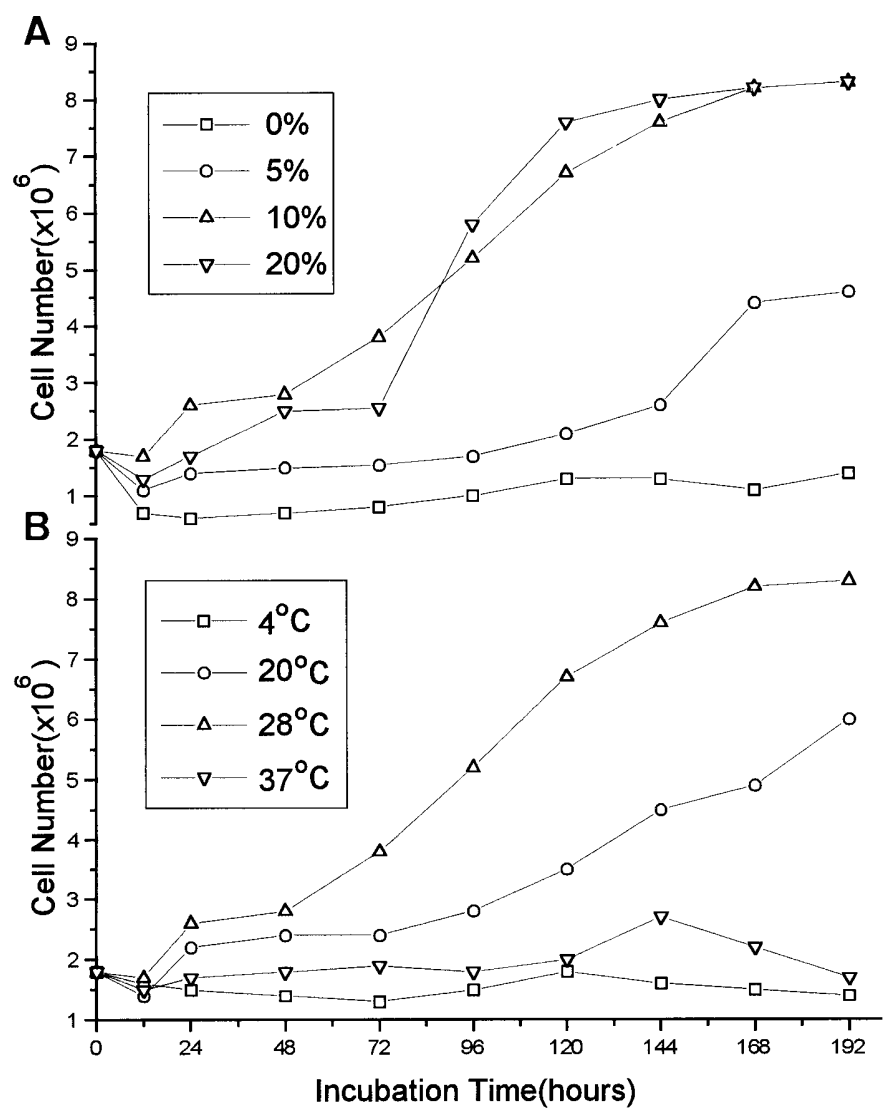

FIG. 3. The influence of cultivation condition on growth rate of NTU-PN-HH cells showing: (A) FBS supplementation (0, 5, 10, and $20 \%)$ at $28^{\circ} \mathrm{C},(\mathrm{B})$ cultivation temperature $\left(4,20,28\right.$, and $\left.37^{\circ} \mathrm{C}\right)$ with $10 \%$ FBS supplement.

species belonging to Lymantriidae (Quiot, 1976; Goodwin et al., 1978). Although an excess of 600 isolates of baculoviruses has been estimated, few of them have been shown to replicate in cultured cells-possibly because investigators have concentrated on viruses and cell lines from insects of economic importance (Kelly, 1982). P. nuda is a major garden pest, causing defoliation of Ficus spp. The insect is oligophagous, and easy to find from fall to early summer. The serious epizootic disease spread by this insect occurs frequently from late spring. It was considered that the pathogen

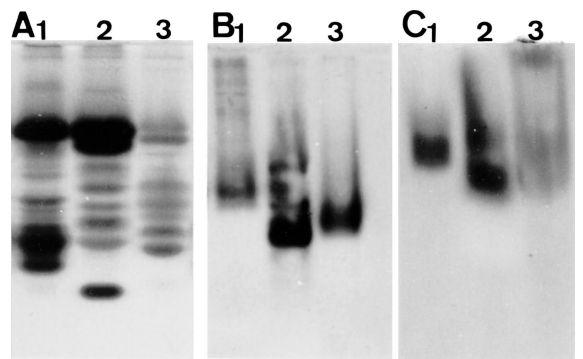

FIG. 4. The isozyme patterns of NTU-PN-HH cells ((A) esterase, (B) $\mathrm{LDH}$, and (C) MDH) (lane 1) compared with IPLB-SF-21AE (lane 2) and IPLB-LD-652Y cells (lane 3).

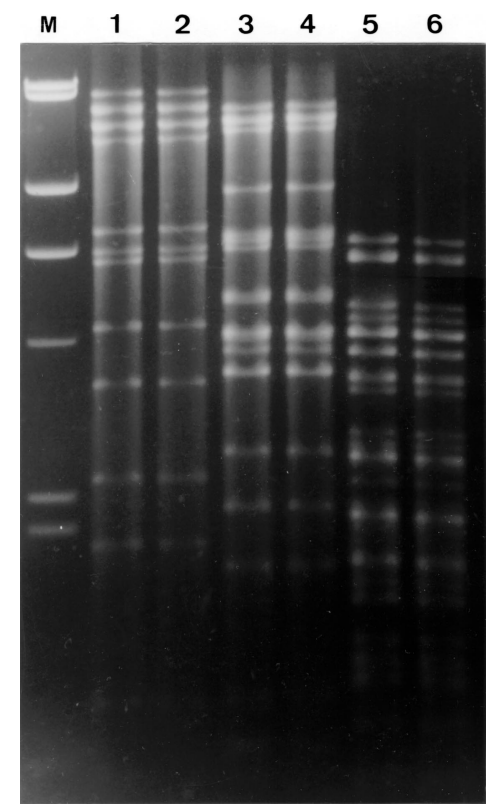

FIG. 5. Restriction endonuclease patterns, EcoRI (lanes 1,2), HindIII (lanes 3,4) and PstI (lanes 5,6), for PnNPV DNAs purified in vivo (lanes 1,3,5) from infected larvae of Perina nuda and in vitro from infected NTU-PN-HH cells (lanes 2,4,6). M indicates the $\lambda$ DNA/ HindIII marker.

PnNPV plays an important role in the natural population control (Wang and Tsai, 1995). IPLB-PN-HH cells, because of their high susceptibility to PnNPV, can provide a suitable in vitro system for study.

The cell line contains four major morphological cell types, no subclones of NTU-PN-HH were obtained in more than 10 clonal tests. It is believed that there is metabolic coupling among the different morphophic cells. The variability in shape of NTU-PN-HH cells is a result either of the variety of originating cells or the cells being inherently pleiomorphic.

Newly established cell lines should be characterized to distinguish them from all other cell lines, determine the tissue from which the line originated, and assure that is not a contaminant (Hink et al., 1985). Tabachnick and Knudson (1980) demonstrated that 10 isozymes are suitable for distinguishing insect cell linesthree were used in this attempt to identify the NTUPN-HH cells. Isozyme patterns reveal that the NTU$\mathrm{PN}-\mathrm{HH}$ cell line is markedly different from other cell lines that are routinely maintained in our lab.

Several established cell lines failed to replicate their homologous viruses or were semipermissive to the homologous virus (Goodwin et al., 1978; Gelernter and Federici, 1986; Quiot, 1976). The homologous virus, PnNPV, successfully propagated in this newly established cell line (NTU-PN-HH). The four types of NTU$\mathrm{PN}-\mathrm{HH}$ cells show similar susceptibility to PnNPV, so the cloned NTU-PN-HH cell is not necessary on the basis of viral susceptibility. Appearance of PnNPV viral progeny in the nucleus and polyhedral formation is 
similar to other NPVs (Fraser and Hink, 1982; Hink and Vail, 1973; Potter et al., 1976). NTU-PN-HH cells also presented a problem with respect to the formation of polyhedra. Continued serial passage of PnNPV in this cell line resulted in an increase in the FP (few polyhedra) strain in PnNPV viral progeny. In regard to viral susceptibility of NTU-PN-HH cells, the MP strain of PnNPV within three passages after end-point dilution purification was selected for this assay. In contrast to the wide host range of AcNPV (Danyluk and Maruniak, 1987), PnNPV was found to be host-specific in vivo and in vitro. It is suggested that the specificity of NPVs is not the result of nutritional factors, but of virus-host relationships concerning receptors or of replication factors (Maeda, 1993) in the virus or cells. The results of comparing the restriction enzyme profiles of PnNPV DNAs purified from two different sources reveals that PnNPV isolated in vitro and in vivo originated from the same NPV.

\section{ACKNOWLEDGMENTS}

We thank Dr. M. J. Fraser, professor at Notre Dame University, for his valuable technical advice throughout our research. This study was supported by the National Science Council, Republic of China.

\section{REFERENCES}

Danyluk, G. M., and Maruniak, J. E. 1987. In vivo and in vitro host range of Autographa californica nuclear polyhedrosis virus and Spodoptera frugiperda nuclear polyhedrosis virus. J. Invertebr. Pathol. 50, 207-212.

Fraser, M. J. 1989. Expression of eucaryotic genes in insect cell cultures. In Vitro Cell. Dev. Biol. 25 (3), 225-235.

Fraser, M. J., and Hink, W. F. 1982. The isolation and characterization of the MP and FP plaque variants Galleria mellonella nuclear polyhedrosis virus. Virology 117, 366-378.

Gelernter, W. D., and Federici, B. A. 1986. Continuous cell line from Spodopera exigua (Lepidoptera: Noctuidae) that supports replication of nuclear polyhedrosis viruses from Spodoptera exigua and Autographa californica. J. Invertebr. Pathol. 48, 199-207.

Goodwin, R. H., Topkins, G. J., Gettig, R. T., and Adams, J. R. 1982. Characterization and culture of virus replicating continuous insect cell lines from the bollworm, Heliothis zea (Boddie). In Vitro 18, 843-850.

Goodwin, R. H., Topkins, G. J., and McCawley, P. 1978. Gypsy moth cell lines divergent in viral susceptibility. In Vitro 14(6), 485-494.

Grace, T. D. C. 1962. Establishment of four strains of cells from insect tissues grown in vitro. Nature 195, 788-789.

Harris, H. D., and Hopkinson, A. 1977. "Handbook of Enzyme Electrophoresis in Human Genetics," pp. 297. North-Holland, Amsterdam.

Hink, W. F. 1970. Established insect cell line from the cabbage looper, Trichoplusia ni. Nature 226, 466-467.

Hink, W. F. 1980. The 1979 compilation of invertebrate cell lines and culture media. In "Invertebrate System in vitro" (E. Kurstak, K. Maramojrosch, and A. Dubendorfer, Eds.), pp. 553-578. Elsevier North-Holland, New York.
Hink, W. F., Ralph, D. A., and Joplin, K. H. 1985. Metabolism and characterization of insect cell cultures. In "Comprehensive Insect Physiology, Biochemistry, and Pharmacology" (G. A. Kerkut and L. I. Giblet, Eds.), pp. 547-570. Pergamon, New York.

Hink, W. F., and Strauss, E. 1976. Growth of the Trichoplusia ni (TN-368) cell line in suspension culture. In "Invertebrate Tissue Culture, Applications in Medicine, Biology, and Agriculture." (E. Kurstak and K. Maramorosch, Eds.), pp. 297-300. Academic Press, New York.

Hink, W. F., and Vail, P. V. 1973. A plaque assay for titration of alfalfa looper nuclear polyhedrosis virus in the cabbage looper (TN-368) cell line. J. Invertebr. Pathol. 22, 168-174.

Kelly, D. C. 1982. Baculovirus replication. J. Gen. Virol. 63, 1-13.

Lo, C. F., Kou, G. H., Wang, C. H., and Shih, C. J. 1990. Studies on baculovirus expression vector system. Natl. Sci. Counc. Mon. (Republic of China) 18, 565-574.

Maeda, S. 1989. Gene transfer vectors of a baculovirus, Bombyx mori nuclear polyhedrosis virus, and their use for expression of foreign genes in insect cells. In "Invertebrate Cell System and Applications” (J. Mitsuhashi, Ed.), pp. 167-181. CRC Press, Boca Raton, FL.

Maeda, S., Kwai, T., Obinata, M., Fujiwara, H., Horiuchi, T., Saeki, Y., and Furusawa, M. 1985. Production of human interferon in silkworm using a baculovilrus vector. Nature 315, 592-594.

Maeda, S., Januta, S. G., and Kondo, A. 1993. Host range expansion of Autographa californica nuclear polyhedrosis virus (NPV) following recombination of a 0.6-kilobase-pair DNA fragment originating from Bombyx mori NPV. J. Virol. 67 (10), 6234-6238.

Potter, K. N., Faulkner, P., and MacKinnon, E. A. 1976. Strain selection during serial passage of Trichoplusia ni nuclear polyhedrosis virus. J. Virol. 18, 1040-1050.

Quiot, J. M. 1976. Establishment of a cell line (SCLD 135) from $L y$ mantria dispar (Lepidoptera) ovaries. C.R. Acad. Sci, Ser. D. 282, 465-467.

Smith, G. E., Summers, M. D., and Fraser, M. J. 1983. Production of human beta interferon in insect cells infected with a baculovirus expression vector. Mol. Cell. Biol. 3, 2156-2165.

Smiths, P. H., and Vlak, J. M. 1988. Selection of nuclear polyhedrosis viruses as biological control agents of Spodoptera exigua (Lepidoptera: Noctuidae). Entomophaga 33 (3), 299-308.

Su, X., Tai, K. C., I, H. T., Shih, M. P., and Hsuan, P. J. 1983. Two nuclear polyhedrosis viruses of two forest insect pests. Scientia Silvae Sinicae, Mem. For. Entomol. 114-115. [in Chinese].

Summers, M. D., and Smith, G. E. 1988. A manual of methods for baculovirus vectors and insect cell culture procedure. Texas Agricultural Experiment Station, No. 1555, pp. 57.

Tabachnick, W. J., and Knudson, D. L. 1980. Characterization of invertebrate cell lines. II. Isozyme analysis electrophoresis. In Vitro 16, 392-398.

Vaughn, J. L., Goodwin, R. H., Tompkins, G. J., and McCawley, P. 1977. The establishment of two cell lines from the insect Spodoptera frugiperda (Lepidoptera: Noctuidae). In Vitro 13, 213-217.

Wang, C. H., and Tsai, S. J. 1995. Life history of the Perina nuda (Fabricius) and virus production of the infected pupae. Chin. J. Entomol. 15, 59-68.

Wu, J., King, G., Daugulis, A. J., Faulkner, P., Bone, D. H., and Goosen, M. F. A. 1989. Engineering aspects of insect cell suspension culture: a review. Microbiol. Biotechnol. 32, 249-255. 